\title{
Leukocytosis and Natural Killer Cell Function Parallel Neurobehavioral Fatigue Induced by 64 Hours of Sleep Deprivation
}

\author{
David F. Dinges, ${ }^{\star *}$ Steven D. Douglas," Line Zaugg," Donald E. Campbell," Joseph M. McMann," Wayne G. Whitehouse," \\ Emily Carota Orne, ${ }^{\star *}$ Shiv C. Kapoor," Edward Icaza, ${ }^{*}$ and Martin T. Orne ${ }^{\star *}$ \\ ${ }^{*}$ Unit for Experimental Psychiatry, The Institute of Pennsylvania Hospital, Philadelphia, Pennsylvania 19139; ${ }^{\ddagger}$ Department of \\ Psychiatry, and "Division of Allergy-Immunology-Infectious Diseases, Department of Pediatrics, University of Pennsylvania School of \\ Medicine; ${ }^{\S}$ Clinical Immunology Laboratory, Childrens Hospital of Philadelphia; 'CRC Laboratory, Hospital of the University of \\ Pennsylvania; and Center for Sleep and Respiratory Neurobiology, University of Pennsylvania School of Medicine, \\ Philadelphia, Pennsylvania 19104
}

\begin{abstract}
The hypothesis that sleep deprivation depresses immune function was tested in $\mathbf{2 0}$ adults, selected on the basis of their normal blood chemistry, monitored in a laboratory for $7 \mathrm{~d}$, and kept awake for $64 \mathrm{~h}$. At $2200 \mathrm{~h}$ each day measurements were taken of total leukocytes (WBC), monocytes, granulocytes, lymphocytes, eosinophils, erythrocytes (RBC), B and T lymphocyte subsets, activated $T$ cells, and natural killer (NK) subpopulations (CD56/CD8 dual-positive cells, CD16-positive cells, CD57-positive cells). Functional tests included NK cytotoxicity, lymphocyte stimulation with mitogens, and DNA analysis of cell cycle. Sleep loss was associated with leukocytosis and increased NK cell activity. At the maximum sleep deprivation, increases were observed in counts of WBC, granulocytes, monocytes, NK activity, and the proportion of lymphocytes in the $S$ phase of the cell cycle. Changes in monocyte counts correlated with changes in other immune parameters. Counts of CD4, CD16, CD56, and CD57 lymphocytes declined after one night without sleep, whereas CD56 and CD57 counts increased after two nights. No changes were observed in other lymphocyte counts, in proliferative responses to mitogens, or in plasma levels of cortisol or adrenocorticotropin hormone. The physiologic leukocytosis and NK activity increases during deprivation were eliminated by recovery sleep in a manner parallel to neurobehavioral function, suggesting that the immune alterations may be associated with biological pressure for sleep. (J. Clin. Invest. 1994.93:1930-1939.) Key words: sleep deprivation • natural killer activity • leukocytes • monocytes $\bullet$ fatigue
\end{abstract}

\section{Introduction}

Sleep loss, endemic in modern society (1), degrades neurobehavioral function (2) and is popularly believed to adversely affect immune function. Although sleep changes often accompany fever and systemic infection, including HIV infection (3), there are few experimental data on immune alterations from sleep deprivation. Limited studies in mice $(4)$ and rats $(5,6)$ have failed to document consistent alterations of immune responses

Address correspondence to Dr. David F. Dinges, Unit for Experimental Psychiatry, University of Pennsylvania School of Medicine, 111 North 49th Street, Philadelphia, PA 19139.

Received for publication 18 October 1993 and in revised form 14 January 1994.

J. Clin. Invest.

(C) The American Society for Clinical Investigation, Inc.

$0021-9738 / 94 / 05 / 1930 / 10 \quad \$ 2.00$

Volume 93, May 1994, 1930-1939 during sleep loss, although death occurred in rats deprived of sleep for 7-32 d (6).

Human studies of sleep deprivation are rare, but they do not have the problem of stressor-induced forced wakefulness required in animal experiments. In 1976, Palmblad and colleagues (7) reported increased interferon production and decreased in vitro phagocytic activity of heparinized blood incubated with Staphylococcus albus after 77 h of wakefulness by 8 women. In a subsequent study of 12 men kept awake for $48 \mathrm{~h}$, they reported decreased lymphocyte proliferation induced by PHA, but no changes in granulocyte adherence to nylon fibers or in granulocyte alkaline phosphatase activity (8). More recently, Moldofsky and colleagues (9) reported that 10 men sleep deprived for $40 \mathrm{~h}$ had elevated nocturnal levels of IL-1and IL-2-like activity, a delayed nocturnal rise in lymphocyte proliferation to pokeweed mitogen (PWM), ${ }^{1}$ but no change in in vitro natural killer cell (NK) activity. In a later study of 6 men deprived for $64 \mathrm{~h}$, they replicated the delayed nocturnal rise in lymphocyte proliferation to PWM, and reported increased NK activity during the early evening hours (10).

Although intriguing, the human studies are limited by small numbers of immune variables and subjects, by the presence of other stressors during sleep loss, and by the absence of data on moderating variables (e.g., body temperature). It is unclear whether sleep deprivation decreases immune function, and whether immune alterations during sleep loss are associated with a stress response or biological pressure for sleep as reflected in neurobehavioral changes during sleep loss. These questions were addressed in an experiment in which immune function, plasma glucocorticoids, and neurobehavioral variables were evaluated in 20 healthy adults who remained awake for $64 \mathrm{~h}$ during $7 \mathrm{~d}$ of continuous in-lab monitoring.

\section{Methods}

\section{Subjects}

A total of 224 female and male young adult volunteers were screened to identify an eligible subset of 20 ( 7 females, 13 males, 21-30 y) who met the following criteria: healthy and free of active infection and symptoms; within normal limits on all parameters in one or more prestudy complete blood cell counts (CBC) and clinical chemistry tests; medication free (including females not using birth control pills); no medical history of cancer, hepatitis, or other serious conditions, including autoimmune disorders; within age-appropriate normal limits in physical and psychological health, sleep-wake pattern, and ease of blood draw.

1. Abbreviations used in this paper: $\mathrm{CBC}$, complete blood cell count; $\mathrm{MCH}$, mean corpuscular hemoglobin; MCHC, mean corpuscular hemoglobin content; MCV, mean corpuscular volume; NK, natural killer; PE, phycoerythrin; PWM, pokeweed mitogen; TC, target cell. 


\section{Sleep deprivation protocol}

The experimental protocol required subjects to live around-the-clock for seven consecutive days $(151 \mathrm{~h})$, under constant supervision, in a comfortable laboratory environment devoid of explicit time cues, and in which temperature $\left(68^{\circ} \mathrm{F}\right)$, light (169 lux), and other environmental factors were held constant. During the first $2 \mathrm{~d}$ subjects were allowed to sleep at night while being monitored polysomnographically. For the next $3 \mathrm{~d}$, subjects remained continuously awake for $64 \mathrm{~h}$. Recovery sleep was allowed on nights 5 and 6.

Throughout all wake periods, the following data were obtained: continuous recordings of body motility and light exposure using Actillumes (Ambulatory Monitoring, Inc., Ardsley, NY); continuous recordings of electroencephalogram and electrooculogram with Medilog 9000 (Oxford Instruments, Clearwater, FL); hourly recordings of sublingual temperature; cognitive performance, mood, and sleepiness every $2 \mathrm{~h}$; fluid intake and voiding; physical and psychological complaints; and continuous observation of behavior and health. Specially trained staff were with subjects at all times to encourage and help them remain awake by mild social activity, and when necessary, by ambulation. Nutritionally balanced meals were provided throughout the protocol, at appropriate times for breakfast, lunch, and dinner, and during sleep deprivation a late night light snack was provided (caffeinated beverages were prohibited at all times). Subjects were paid $\$ 600$ at the completion of the experiment, which they understood they could withdraw from at any time without jeopardy; no subject withdrew from the study or had to be withdrawn for an adverse reaction. The protocol was approved by the Human Subjects Committee of the Pennsylvania Hospital.

\section{In vitro assays}

Blood samples. Fig. 1 schematically presents the timing of blood draws in the protocol. Blood samples were collected at $2200-2230 \mathrm{~h}$ on the predeprivation baseline (B15) day, on each of the deprivation (SD15, SD39, SD63) days, and on the first recovery (R15) day (for logistic reasons waking blood draws before and after these $5 \mathrm{~d}$ were taken at $2100 \mathrm{~h}$ ). (During these $5 \mathrm{~d}$ blood was also taken at 0100-0130 h, when subjects slept during baseline and recovery nights, and during wakefulness on deprivation nights; these sleep-wake results are not reported.) In all cases, blood was drawn by venipuncture from the antecubital fossa. At each of the 13 blood draws two $20-\mathrm{ml}$ blood samples per subject were collected in a heparinized (preservative free) (LyphoMed, Inc., Rosemont, IL) syringe and in an anticoagulant-free syringe. For the 2200-2300-h wake blood draws reported here, subjects were in a sitting position. $2 \mathrm{ml}$ of the heparinized blood were removed for lymphocyte phenotype analysis, the remainder was used for measurement of NK activity, mitogen stimulation, and DNA analysis. The anticoagulant-free blood was immediately transferred into a 10 -ml red cap vacutainer tube (Becton Dickinson Vacutainer Systems, Rutherford, NJ) for serum studies and two 5-ml lavender cap tubes containing $0.05-\mathrm{ml}$ of $15 \%$ EDTA $\left(\mathrm{K}_{3}\right)$ solution $(7.5 \mathrm{mg})$ : one for $\mathrm{CBC}$ and one for plasma assessment. All assays were performed by laboratory personnel blind to the identity of the samples.

$C B C$. CBC (WBC, granulocytes, monocytes, RBC, platelet count, hemoglobin, hematocrit, mean corpuscular volume [MCV], mean corpuscular hemoglobin $[\mathrm{MCH}]$, mean corpuscular hemoglobin content [MCHC], and differential) were performed using standard methods
(STKA, Coulter Corp., Hialeah, FL) by an independent clinical laboratory (Damon Clinical Laboratories, Trevose, PA). CBC were performed on $90 \%$ of samples in $<6 \mathrm{~h}$ (maximum $12 \mathrm{~h}$ ). WBC counts were also determined on site as a quality control check.

Lymphocyte preparation and distribution. PBMC were obtained using a Ficoll-Paque gradient (Pharmacia Biotechnology Inc., Piscataway, NJ) (11). Cells were washed twice with PBS (Gibco Life Technologies Inc., Grand Island, NY) and resuspended in RPMI medium (Cellgro, Mediatech, Washington, DC) enriched with $15 \%$ normal human serum (Gibco) (inactivated $1 \mathrm{~h}$ in a $56^{\circ} \mathrm{C}$ water bath) and $100 \mathrm{U} / \mathrm{ml}$ of penicillin (Gibco), $100 \mu \mathrm{g} / \mathrm{ml}$ of streptomycin (Gibco), and $0.29 \mathrm{mg} / \mathrm{ml}$ of L-glutamine (Gibco). The cell suspension was adjusted to $1 \times 10^{7}$ cells/ml for NK activity assessment and to $1 \times 10^{6}$ cells $/ \mathrm{ml}$ for mitogen-stimulated cultures and DNA analysis. Cell viability was $>98 \%$ (tested by Trypan Blue, Gibco).

Cell phenotyping and enumeration. Flow cytometry was used to enumerate subpopulations of B cells (CD20) and the following T cells: T helper (CD4) and T suppressor (CD8) cells, inducer-helper (CD29) and inducer-suppressor (CD45RA) cells, and activated T cells (HLADR receptor). NK cell numbers were analyzed using three different mAbs (CD56, CD57, CD16), in an effort to identify all NK-related cells. CD56 cells were enumerated by a dual-color mAb that costained positively for CD8. Enumerations of CD57 and CD16 phenotypes were added as the experiment progressed and were accomplished by singlecolor markers, respectively. As summarized in Table I, lymphocyte phenotyping was performed with mAbs from Coulter Corp. and from Becton Dickinson (Immunocytometry Division, San Jose, CA) (12). All mAbs were directly conjugated with FITC or phycoerythrin (PE). $100 \mu \mathrm{l}$ of heparinized blood was added to $10 \mu \mathrm{l}$ of mAbs. Coulter Corp. methodology was performed to prepare the samples; $30 \mathrm{~min}$ of incubation was used for whole blood and antibodies. Analysis was performed with an EPICS Profile II flow cytometer (Coulter Corp.).

Mitogen-induced lymphocyte stimulation. PBMC were cultured with PHA (Wellcome Diagnostics, Dartford, England), ConA (Sigma Chemical Co., St. Louis, MO), and PWM (Gibco) (13). $100 \mu \mathrm{l}$ of PBMC suspension $\left(1 \times 10^{6} \mathrm{cells} / \mathrm{ml}\right)$ was cultured in triplicate in flatbottom 96-well plates (Fisher Scientific Co., Malvern, PA) with $100 \mu \mathrm{l}$ of mitogen. Mitogen concentrations were used that yielded the optimal response: $1 \mu \mathrm{g} / \mathrm{ml}$ for PHA, $30 \mu \mathrm{g} / \mathrm{ml}$ for ConA, and $1 \mu \mathrm{g} / \mathrm{ml}$ for PWM. The plates were incubated at $37^{\circ} \mathrm{C}$ and $5 \% \mathrm{CO}_{2}$ for $70 \mathrm{~h}$ (PHA and ConA) and for $118 \mathrm{~h}$ (PWM). $1 \mu \mathrm{Ci} /$ well of $\left[{ }^{3} \mathrm{H}\right]$ thymidine (ICN Biomedical Inc., Irvine, CA) was added for $20 \mathrm{~h}$ before harvesting on fiberglass paper (cell harvester, Brandel Biomedical, Inc., Gaithersburg, MD). The samples were counted in a liquid scintillation counter (Wallac Oy, Turku, Finland), and the data were expressed as counts per minute of stimulated culture minus the counts per minute of unstimulated culture.

NK cell activity. NK activity was assessed utilizing a modification $(14,15)$ of standard techniques. The cell line K-562 was used as the target cell (TC). Cells were maintained in a RPMI 1640 medium enriched with $10 \%$ FCS (Gibco) (inactivated $1 \mathrm{~h}$ in a $56^{\circ} \mathrm{C}$ water bath) and $100 \mathrm{U} / \mathrm{ml}$ of penicillin (Gibco), $100 \mu \mathrm{g} / \mathrm{ml}$ of streptomycin (Gibco) and $0.29 \mathrm{mg} / \mathrm{ml}$ of L-glutamine (Gibco). TC were washed twice with the media and resuspended in $1 \mathrm{ml}$, after which they were incubated with $0.5 \mathrm{ml}$ of $\mathrm{Na}_{2}{ }^{51} \mathrm{CrO}_{4}\left({ }^{51} \mathrm{Cr}\right.$; Dupont NEN, Boston, MA) at $37^{\circ} \mathrm{C}$ and $5 \% \mathrm{CO}_{2}$ for $2 \mathrm{~h}$. After incubation TC were washed twice and ad-

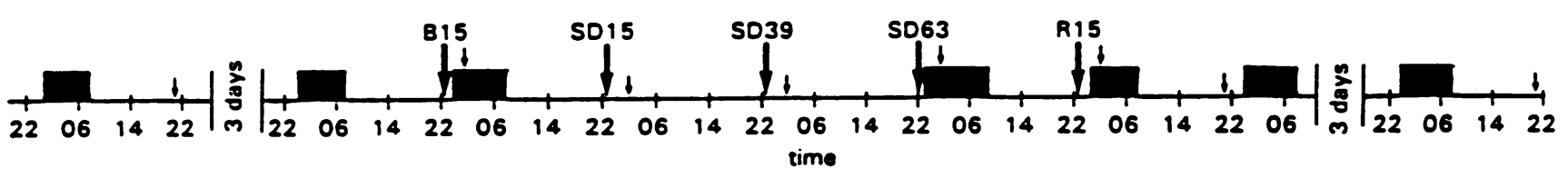

Figure 1. Schematic time line of sleep deprivation protocol, showing periods of nocturnal sleep (black bars) and times of blood draws (downward arrows) between 2200 and $2230 \mathrm{~h}$ on each of five consecutive days (predeprivation baseline [B15], day 1 of deprivation [SD15], day 2 of deprivation [SD39], day 3 of deprivation [SD63], and the first day after recovery sleep [R15]). Results are not reported here for blood draws designated by smaller arrows (taken $3 \mathrm{~d}$ before and following the experimental phase, as well as at $0100-0130 \mathrm{~h}$ each day, and at $2100 \mathrm{~h}$ on the last day of the protocol). 
Table I. Monoclonal Antibodies Used for Lymphocyte Phenotyping

\begin{tabular}{|c|c|c|}
\hline Cell type & Monoclonal antibody & Source \\
\hline Monocyte/Pan leukocyte & CD14-PE/CD45-FITC & Coulter \\
\hline Pan T cells (E-rosette)/Pan B cells & CD2-PE/CD20-FITC & Coulter \\
\hline Inducer $\mathrm{T}$ cells/suppressor/cytotoxic $\mathrm{T}$ cells & CD4-PE/CD8-FITC & Coulter \\
\hline Helper-inducer subset/inducer $\mathrm{T}$ cells & CD29-PE/CD4-FITC & Coulter \\
\hline Suppressor-inducer subset/inducer $\mathrm{T}$ cells & CD45RA-PE/CD4-FITC & Coulter \\
\hline Natural killer cells/suppressor/cytotoxic $\mathrm{T}$ cells & CD56-PE/CD8-FITC & Coulter \\
\hline Immunocompetent $\mathrm{T}$ cells/activated $\mathrm{T}$ and $\mathrm{B}$ cells, monocytes & $\begin{array}{l}\text { CD3-PE/34, 29Kd-FITC (CD No. } \\
\text { not assigned) }\end{array}$ & Coulter \\
\hline NK cells & CD57-FITC & Becton Dickinson \\
\hline \multirow[t]{3}{*}{ NK cells } & CD16-FITC & Becton Dickinson \\
\hline & Control monoclonal antibody & \\
\hline & $\begin{array}{l}\text { Mouse } \mathrm{IgG}_{1}-\mathrm{PE} / \mathrm{Mouse}_{\mathrm{IgG}}-\mathrm{FITC} \\
\text { Mouse } \mathrm{IgG}_{1}-\mathrm{PE} / \text { Mouse } \mathrm{IgG}_{2 \mathrm{a}}-\text { FITC } \\
\text { Mouse IgM-FITC }\end{array}$ & $\begin{array}{l}\text { Coulter } \\
\text { Coulter } \\
\text { Coulter }\end{array}$ \\
\hline
\end{tabular}

justed to $1 \times 10^{5}$ cell $/ \mathrm{ml}$; cell viability was $>96 \%$ (tested with Trypan Blue). After $100 \mu \mathrm{l}$ of $1 \times 10^{7} \mathrm{PBMC} / \mathrm{ml}$ were incubated in triplicate with $100 \mu \mathrm{l}$ of labeled target cells for $4 \mathrm{~h}$ at $37^{\circ} \mathrm{C}$ and $5 \% \mathrm{CO}_{2}$ (effector/ target ratio was 100:1), $100 \mu \mathrm{l}$ of the supernatants was harvested and counted in a gamma counter (Beckman Instruments Inc., Fullerton, CA). NK activity was calculated as ([sample activity - spontaneous release]/[total release - spontaneous release]) $\times 100$. Total release of ${ }^{51} \mathrm{Cr}$ was done with $100 \mu \mathrm{l}$ of a $5 \%$ Triton solution and the TC. Spontaneous release was performed with $100 \mu$ l of media and the TC. Results were expressed in percent specific cytotoxicity.

DNA analysis. Flow cytometry was used to quantitate the proportion of PBMC in each phase of the cell cycle, to provide an additional sensitive measure of lymphocyte mitogenic events (16). $500 \mu \mathrm{l}$ of PBMC $\left(1 \times 10^{6}\right.$ cells $\left./ \mathrm{ml}\right)$ were incubated with $500 \mu \mathrm{l}$ of PHA $(1 \mu \mathrm{l} / \mathrm{ml})$ for 22,46 , and $70 \mathrm{~h}$, and with $500 \mu \mathrm{l}$ of RPMI medium (prepared as described above) for 0 and $70 \mathrm{~h}$. After incubation at $37^{\circ} \mathrm{C}$ and $5 \% \mathrm{CO}_{2}$, the supernatants were aspirated, leaving the cell pellets. The cell pellets were resuspended and fixed with 70\% ethanol (Mallinckrodt Inc., Paris, KY), then washed twice with $2 \mathrm{ml}$ of PBS, and $0.5 \mathrm{ml}$ of $5 \%$ propidium iodide (Sigma Chemical $\mathrm{Co}$.) was added. They were then incubated at $4^{\circ} \mathrm{C}$ for $60 \mathrm{~min}$. The samples were then analyzed using an EPICS Profile II flow cytometer for determinination of the fluorescence intensity of each cell, which is directly proportional to the amount of DNA in the nucleus of the cell. All histograms were transferred to the networked computer for cell cycle analysis (Multicycle, Phoenix Flow System, San Diego, CA). The results were expressed as the relative percentages of cells in each of the cell cycle phases: $\left(G_{0} / G_{1}\right.$ $=$ pre-DNA synthesis phase; $S=$ DNA synthesis phase; and $G_{2}=$ postDNA synthesis phase).

Glucocorticoid assays. To determine the extent to which sleep deprivation activated the hypothalamic-pituitary-adrenal axis, plasma levels of cortisol and ACTH from frozen serum $\left(-70^{\circ} \mathrm{C}\right)$ were evaluated throughout the protocol in 12 subjects by standard RIA kits (Diagnostic Products Corp., Los Angeles, CA).

\section{Data analyses}

One-way analysis of variance corrected for sphericity using Greenhouse-Geisser epsilon was used to evaluate whether there was a statistically significant $(P \leq 0.05)$ variation in each dependent variable across $5 \mathrm{~d}$ : from baseline (B15) through $3 \mathrm{~d}$ without sleep (SD15, SD39, SD63) and after a recovery night of sleep (R15). For significant $F$ ratios, single degree-of-freedom polynomial tests of order were conducted to determine the presence of significant linear, quadratic, cubic, and fourthorder profiles in the data, and critical difference comparisons were carried out among means using Newman-Keuls' Critical Difference Test. Spearman rank order correlations $(P \leq 0.05$, two-tailed criteria) were used to determine whether change scores (not normally distributed) across sleep-deprivation days (SD63 minus SD15) were correlated with change scores in other immune parameters that varied significantly across days. Additional analyses on the effects of recovery sleep were conducted using dependent $t$ tests (two-tailed criteria).

\section{Results}

Clinical examinations. Twice daily exams (one by a nurse and one by a physician) revealed no signs or symptoms of viral or bacterial infection in subjects, and no febrile responses were obtained on any of the sublingual temperature recordings taken on each subject every $2 \mathrm{~h}$ throughout the waking portions of the protocol. There was no systematic evidence of viral or bacterial infection (e.g., upper respiratory illness) in subjects at an evaluation $3 \mathrm{~d}$ after the protocol, as well as in daily logs completed by subjects for $9 \mathrm{~d}$ after the study.

Neurobehavioral measures. The sleep deprivation manipulation had the expected adverse effects on neurobehavioral outcomes. Fig. 2 displays data for two sleepiness (top panel) and cognitive performance (second panel) obtained every $2 \mathrm{~h}$ throughout all waking periods of the protocol. The panels show only the results obtained at the 2200-h tests each day, which took place within a few minutes of the $2200-h$ blood draws. As is evident in the top panel of Fig. 2, sleepiness ratings as measured by the Stanford Sleepiness Scale (17) increased across days of sleep deprivation, and declined after a night of recovery sleep $\left(F_{4,76}=18.4, P=0.0001\right)$. The polynomial profile for these ratings contained significant quadratic $(P=0.0001)$ and cubic $(P=0.0001)$ components. Similar results were found for fatigue ratings from analog scales and adjective checklists completed throughout the protocol.

A comparable pattern seen in the second panel of Fig. 2 was obtained for vigilance lapses on a sustained-attention reaction time performance task that is well documented to be sensitive to sleep loss (18-20). Lapses (reaction times $\geq 500 \mathrm{~ms}$ ) increased with consecutive days of sleep loss and were reduced after recovery sleep $\left(F_{4,76}=48.1, P=0.00001\right)$. The profile included significant linear $(P=0.0001)$, quadratic $(P$ 

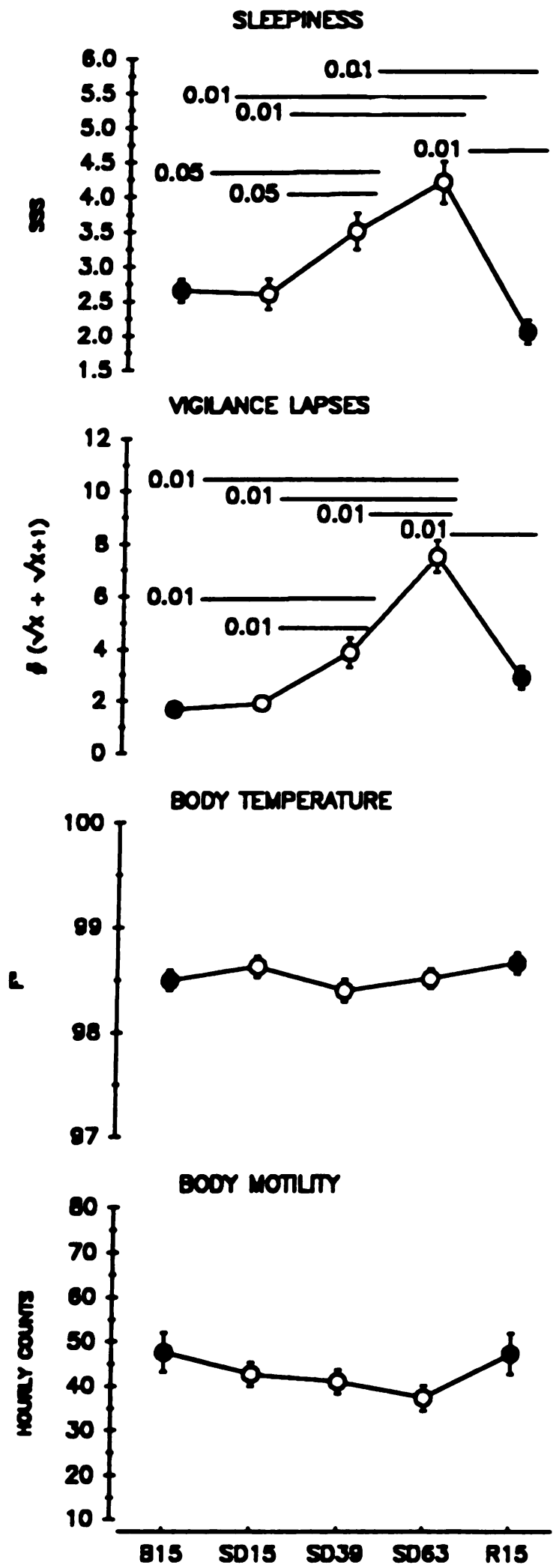

Figure 2. Means (SEM) for subjective sleepiness ratings (higher values indicate greater sleepiness), numbers of vigilance performance lapses, sublingual body temperature, and body motility counts (2100-2200 h) from 20 healthy young adults. Sleepiness, performance, and temperature data were obtained immediately before $2200 \mathrm{~h}$ blood draws on each of five consecutive days: predeprivation baseline day after 15 $\mathrm{h}$ awake (B15), first day of sleep deprivation after $15 \mathrm{~h}$ awake (SD15), second day of sleep deprivation after $39 \mathrm{~h}$ awake (SD39), third day
$=0.0001)$, cubic $(P=0.0001)$, and 4th-order $(P=0.002)$ components.

In contrast to neurobehavioral variables, body temperature and body motility immediately before blood draws at $2200 \mathrm{~h}$ (see bottom two panels of Fig. 2) did not show significant variation between days. Body temperature, assessed sublingually, was comparable across days at the time blood was taken $\left(F_{4,76}\right.$ $=1.8$ ). Body motility, assessed actigraphically, also showed no reliable variation for the values from $2200-2300 \mathrm{~h}$ across days of sleep deprivation and recovery $\left(F_{4,72}=1.6\right)$. Both body temperature and to a lesser extent, body motility, showed robust circadian (within-a-day) variation, as did the neurobehavioral outcomes. The pattern of results presented in Fig. 2 suggests circadian rhythms during sleep loss did not yield significant differences in body temperature or motility at $2200 \mathrm{~h}$ each day. This was confirmed by visual inspection of circadian body temperature curves, which suggested that the 2200-h blood draws occurred at the same circadian phase each day.

$C B C$ and cell phenotype enumeration. RBC counts decreased across consecutive days of the study $\left(F_{4,76}=13.9, P\right.$ $=0.0001$ ) in a manner consistent with hemodilution. The decreases were linear $(P=0.0001)$ and of relatively small magnitude (highest count on B15, $M=4.967 \times 10^{6} / \mathrm{mm}^{3}$; lowest count on R15, $M=4.741 \times 10^{6} / \mathrm{mm}^{3}$; difference $=4.5 \%$ ). Hemoglobin $\left(F_{4,76}=10.4, P=0.0001\right)$, hematocrit $\left(F_{4,76}\right.$ $=13.8, P=0.0001)$, and $\operatorname{MCV}\left(F_{4,76}=5.7, P=0.002\right)$ paralleled the linear declines in RBC counts across days, but no systematic variation was observed for platelet count, $\mathrm{MCH}$, or MCHC.

Total WBC counts increased across days of sleep loss and partially returned to predeprivation levels after recovery sleep $\left(F_{4,76}=5.9, P=0.002\right)$, reflecting both linear $(P=0.01)$ and 4th-order $(P=0.002)$ polynomial components. There was an increase of $12.7 \%$ from predeprivation (B15, $M=7.38 \times 10^{3}$ / $\mathrm{mm}^{3}$ ) to maximum deprivation (SD63, $M=8.32 \times 10^{3} / \mathrm{mm}^{3}$ ). Significant increases during deprivation were also observed for the numbers of granulocytes $\left(F_{4,76}=7.3, P=0.001\right)$ and monocytes $\left(F_{4,76}=8.4, P=0.0005\right)$, but not for the numbers of lymphocytes $\left(F_{4,76}=2.1\right)$ or eosinophils $\left(F_{4,76}=1.7\right)$. Results for granulocytes, lymphocytes, and monocytes are shown in Fig. 3. The profile for granulocyte numbers contained linear $(P$ $=0.001)$, cubic $(P=0.037)$, and 4 th-order $(P=0.014)$ components. Similarly, the profile for monocyte counts contained linear $(P=0.001)$ and cubic $(P=0.017)$ components. The increase in mean values across deprivation (from B15 to SD63) was $22.6 \%$ for granulocyte numbers and $22.7 \%$ for monocyte counts.

Consistent with a lack of change in total lymphocyte counts, there were no statistically significant effects over time found for the numbers of B lymphocytes $\left(F_{4,76}=1.3\right)$ and $T$ lymphocytes $\left(F_{4,76}=2.1\right)$. The enumeration of $\mathrm{T}$ cell subsets

of deprivation after $63 \mathrm{~h}$ awake (SD63), and the first day after recovery sleep after $15 \mathrm{~h}$ awake (R15). Data from days on which sleep was deprived are designated by open circles (SD15, SD39, SD63). Horizontal lines show the results of critical difference comparisons (Newman-Keuls' Tests) carried out among means for those variables in which a statistically significant $F$-ratio was obtained from analysis of variance across days. Means that differ significantly have a horizontal line in common, with the significance level of the difference shown at one end of the line. 

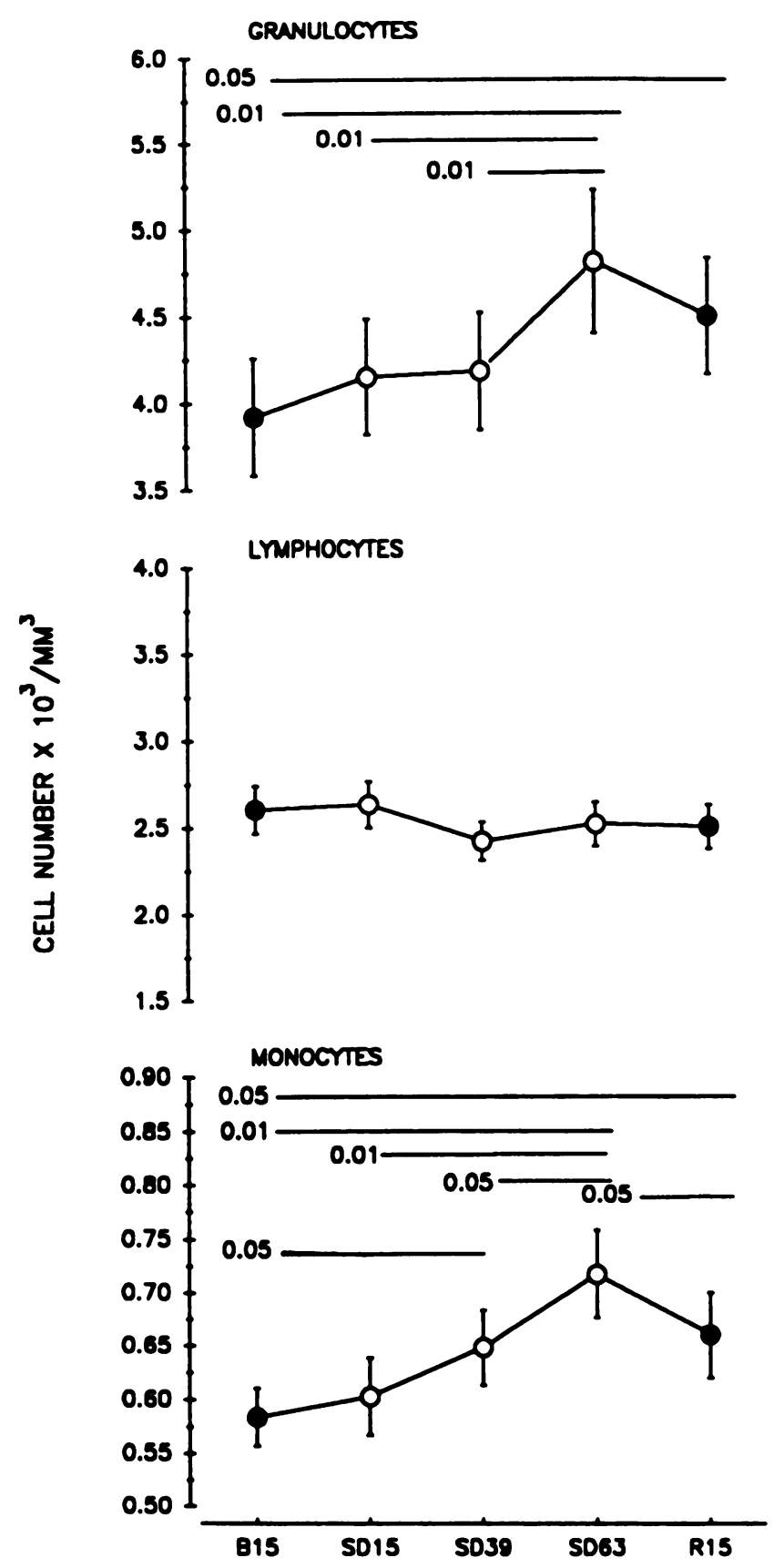

Figure 3. Means (SEM) for granulocyte counts, lymphocyte counts, and monocyte counts from 20 healthy young adults. See Fig. 2 for explanation of graph.

also yielded negative results for activated $\mathrm{T}$ cells $\left(F_{4,76}=1.4\right), \mathrm{T}$ suppressor cells $\left(F_{4,76}=1.7\right)$, inducer-helper $\left(F_{4,76}=0.6\right)$, and inducer-suppressor cell counts $\left(F_{4,76}=1.5\right)$.

In contrast, $T$ helper cell (CD4) counts decreased across days $\left(F_{4,76}=3.0, P=0.041\right)$ in a linear profile $(P=0.033)$. Although there were no significant differences among CD4 means on the Newman-Keuls' Test, a dependent $t$ test revealed that the decrease in $\mathrm{T}$ helper cell counts from predeprivation (SD15 $M=1,220 / \mathrm{mm}^{3}$ ) to deprivation (SD39 $M=1,120$ / $\mathrm{mm}^{3}$ ) was statistically significant $(t=2.23, P=0.038)$. CD4 counts tended to remain lower at maximum deprivation (SD63 $\left.M=1,120 / \mathrm{mm}^{3}\right)$ relative to predeprivation $\operatorname{SD} 15(t=1.76, P$ $=0.094)$.
NK cell counts showed systematic variation across days for $\operatorname{CD56}\left(F_{4,76}=4.9, P=0.005\right), \operatorname{CD} 57\left(F_{4,44}=3.8, P=0.049\right)$, and $\operatorname{CD} 16\left(F_{4,12}=7.7, P=0.047\right)$ subsets. The bottom panels of Fig. 4 display the results for CD56 and CD57. In both cases the data were best characterized by a 4 th-order polynomial profile (CD56, $P=0.0001$; CD57, $P=0.001$ ). Newman-Keuls' comparisons between means revealed significant increases $(P$ $=0.05$ ) from SD39 to SD63 in CD56 counts $(28.8 \%)$ and CD57 counts (33.6\%), and significant increases between SD39 and R15 (CD56 = 34.9\%; CD57 = 35.6\%). The apparent decreases in CD56 counts and CD57 counts from predeprivation (SD15) to after a night without sleep (SD39) were not significant by Newman-Keuls' tests, but were significant by dependent $t$ test comparisons for both CD56 $(t=2.47, n=19, P$ $=0.023)$ and CD57 counts $(t=2.64, n=11, P=0.023)$. However, this decrease across the first night without sleep was significant $(P=0.01)$ by Newman-Keuls' test for CD16 cell counts $(32.0 \%)$ for the four subjects on which data were available. The decrease appeared to be the result of the value at SD1 5 being significantly above CD16 counts on all other days, including baseline (Newman-Keuls' tests). Unlike CD56 and CD57 counts, however, CD16 counts remained lower at maximum deprivation (SD63) and increased after recovery (R15). These latter changes were not significant by Newman-Keuls' comparisons, but they reached the 0.05 level for more liberal dependent $t$ tests.

NK cell activity. Results for NK activity are shown in the top panel in Fig. 4. NK activity varied significantly across days $\left(F_{4,76}=9.7, P=0.0005\right)$; there was a $13.9 \%$ increase in cytotoxicity from predeprivation (B15) to maximum deprivation (SD63). Similar to vigilance lapses (Fig. 1), all polynomial tests were significant for NK activity: linear $(P=0.0001)$, quadratic $(P=0.027)$, cubic $(P=0.024)$, and 4th-order $(P=0.042)$ profiles. Newman-Keuls' tests among means revealed that NK activity at SD63 was significantly greater than NK activity at all other time points, a result also obtained for subjective sleepiness, vigilance lapses (Fig. 2), and monocyte counts (Fig. 3).

Lymphocyte proliferation. In vitro lymphocyte proliferative responses to PHA, ConA, and PWM showed little systematic variation across days. Nonsignificant outcomes were obtained for lymphocyte responses to ConA after $70 \mathrm{~h}$ of incubation $\left(F_{4,76}=2.4\right)$, for PWM after $118 \mathrm{~h}$ of incubation $\left(F_{4,72}=1.4\right)$, and for PHA after $24 \mathrm{~h}\left(F_{4,28}=1.3\right)$ and $70 \mathrm{~h}\left(F_{4,72}=1.2\right)$ of incubation. There was significant variation across days in response to PHA at $48 \mathrm{~h}$ of incubation $\left(F_{4,44}=4.9, P=0.024\right)$, but this effect was due to a drop in proliferative response between B15 and all subsequent time points, including SD15, which was equal to $\mathrm{B} 15$ in wake time.

DNA analyses. Although lymphocyte proliferative responses appeared unaffected by sleep loss, analysis of DNA to quantitate the proportion of lymphocytes in each phase of the cell cycle revealed some significant changes with sleep loss. Significant effects were found for DNA analysis of lymphocytes incubated in PHA for 22, 46, and $70 \mathrm{~h}$. Incubation for 22 $h$ resulted in no changes in cell percentages in $G_{0} / G_{1}$ phase $\left(F_{4,60}=2.1\right)$ or $\mathrm{G}_{2}$ phase $\left(F_{4,60}=2.3\right)$, but there was a significant increase in the proportion of cells in $\mathrm{S}$ phase as sleep loss progressed $\left(F_{4,60}=2.9, P=0.044\right)$, following a linear $(P=0.004)$ profile. Results for $46 \mathrm{~h}$ of incubation were negative for cell percentages in the $\mathrm{G}_{0} / \mathrm{G}_{1}$ phase $\left(F_{4,76}=2.5\right), \mathrm{G}_{2}$ phase $\left(F_{4,76}\right.$ $=2.6)$, and $\mathrm{S}$ phase $\left(F_{4,76}=0.9\right)$. However, at $70 \mathrm{~h}$ incubation in PHA, sleep loss affected the proportion of cells in each phase 

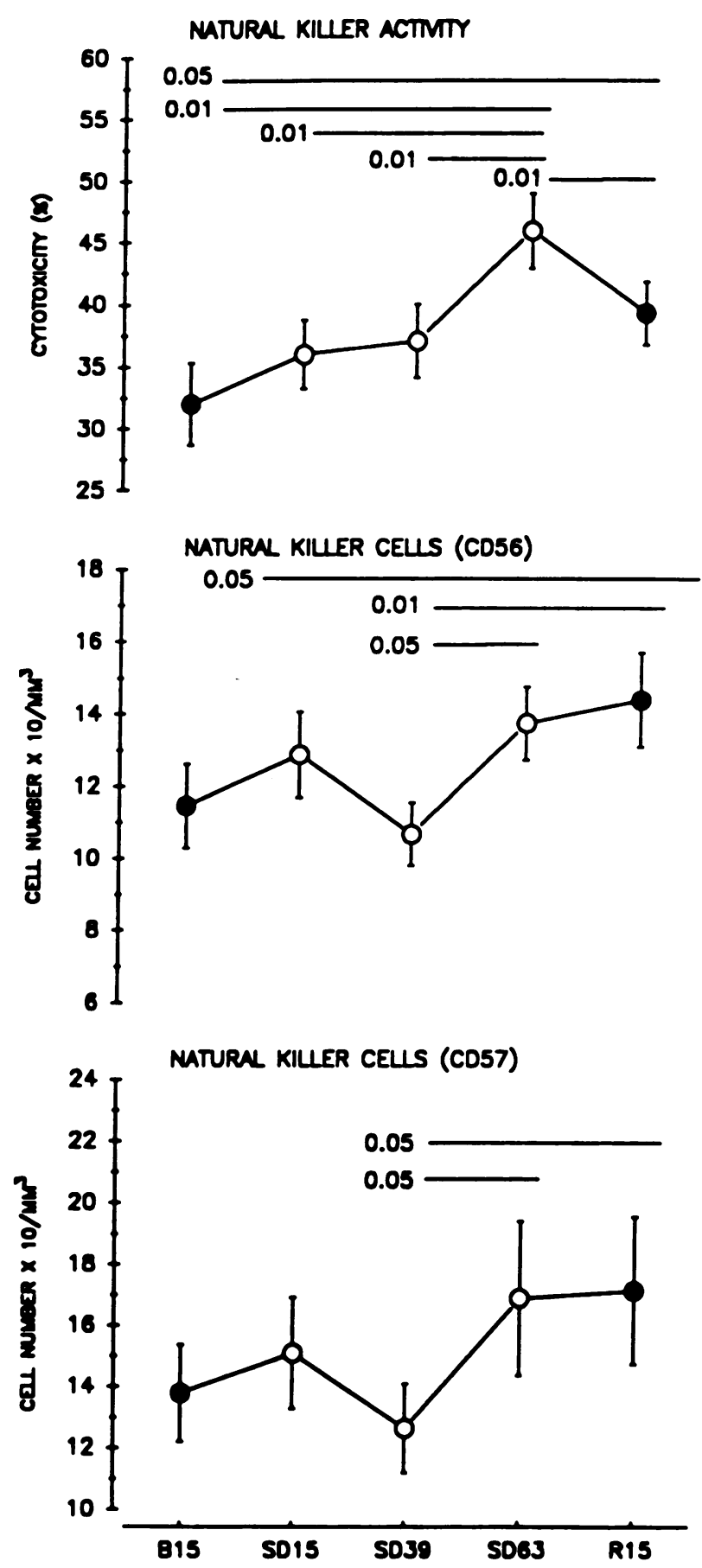

Figure 4. Means (SEM) for NK cell activity, and counts of CD56 and CD57 cells from 20 healthy young adults. See Fig. 2 for explanation of graph.

of the cell cycle: decreasing the percentage in $\mathrm{G}_{0} / \mathrm{G}_{1}\left(F_{4,76}=\right.$ $2.8, P=0.048)$ in a linear manner $(P=0.035)$; increasing the percentage in $\mathrm{G}_{2}\left(F_{4,76}=3.6, P=0.023\right)$ (significant quadratic and 4th-order profile); and increasing the proportion in $S$ phase $\left(F_{4,76}=6.5, P=0.001\right)$ in a profile with linear $(P=0.002)$ and quadratic $(P=0.019)$ components. Results for $S$ phase cell percentages after $70 \mathrm{~h}$ of incubation in PHA are shown in the top panel of Fig. 5.

No systematic variation over time was found at $0 \mathrm{~h}$ of incubation in RPMI control medium for percentages of cells in
$\mathrm{G}_{0} / \mathrm{G}_{1}$ phase $\left(F_{4,72}=1.7\right), \mathrm{G}_{2}$ phase $\left(F_{4,72}=0.5\right)$, or $\mathrm{S}$ phase $\left(F_{4,72}=2.0\right)$. At $70 \mathrm{~h}$ of incubation, however, there were signifcant decreases across deprivation in the percentage of cells in $\mathrm{G}_{0} / \mathrm{G}_{1}$ phase $\left(F_{4,76}=12.7, P=0.0005\right)$, and significant increases in the percentage of cells in S phase $\left(F_{4,76}=12.8, P\right.$ $=0.0005)$. The $\mathrm{S}$ phase profile reflected both quadratic $(P$ $=0.0001)$ and cubic $(P=0.032)$ components. Results for $\mathrm{S}$ phase at 0 and $70 \mathrm{~h}$ of incubation in RPMI are shown in the bottom two panels of Fig. 5 .

Glucocorticoid analyses. Plasma levels of cortisol varied systematically across deprivation $\left(F_{4,44}=3.8, P=0.022\right)$ with both linear $(P=0.032)$ and quadratic $(P=0.041)$ components. However, the pattern was not associated with sleep deprivation. Instead, cortisol levels were higher on baseline (B15) and recovery (R15) days than on any sleep deprivation day. The
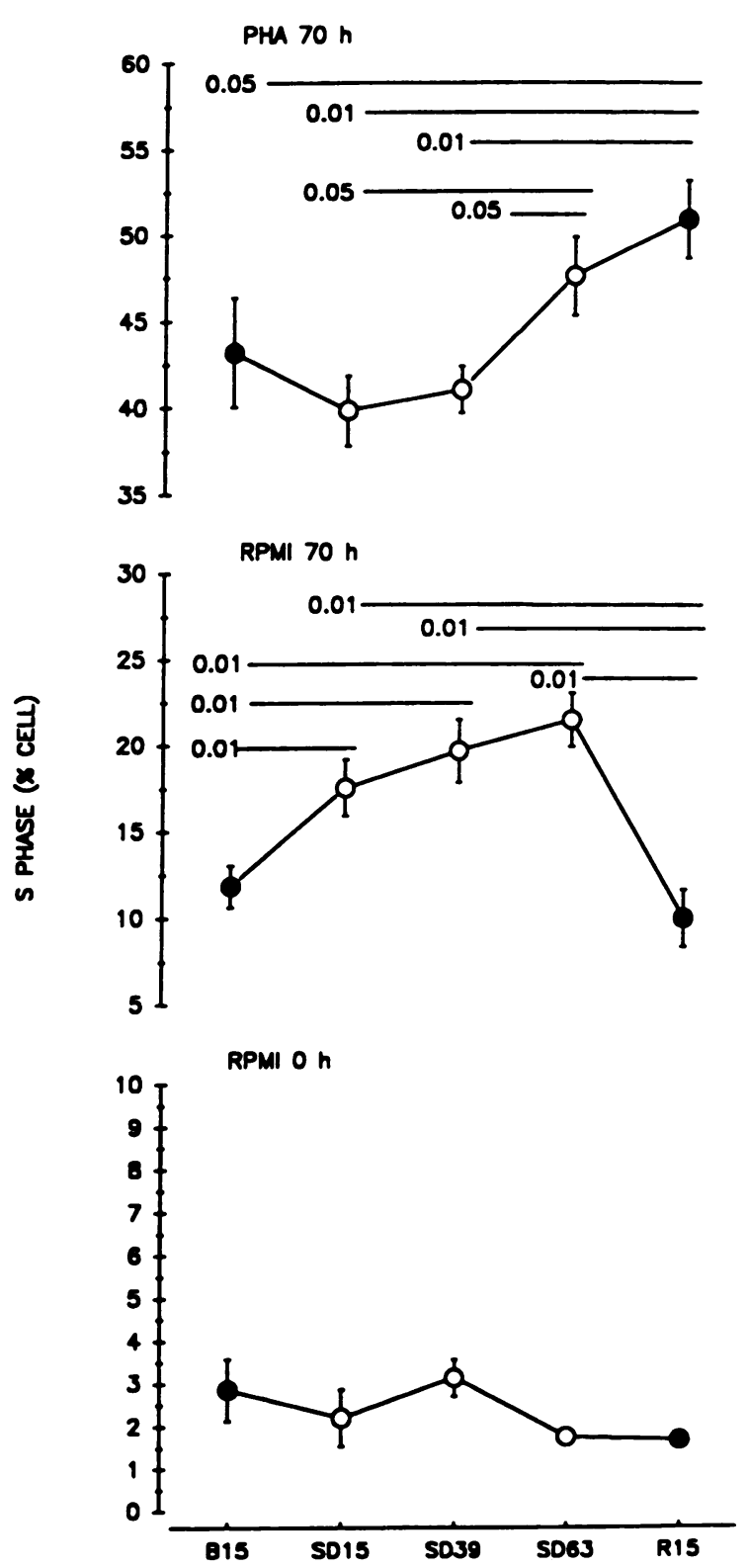

Figure 5. Means (SEM) for the proportion of lymphocytes in the $\mathrm{S}$ phase of the cell cycle after $70 \mathrm{~h}$ of incubation with PHA, $70 \mathrm{~h}$ incubation in control medium (RPMI), and $0 \mathrm{~h}$ of incubation in control medium (RPMI). See Fig. 2 for explanation of graph. 
Table II. Spearman Correlation Coefficients between $(n=20)$ Change Scores (SD63 to SD15) in Immune Parameters across Sleep Deprivation

\begin{tabular}{|c|c|c|c|c|c|c|}
\hline & Granulocytes & Monocytes & $\begin{array}{c}\mathrm{NK} \\
\text { (CD56) }\end{array}$ & $\begin{array}{c}\text { NK } \\
\text { activity }\end{array}$ & $\begin{array}{l}\text { RPMI }(70 h) \\
\text { S phase }\end{array}$ & $\begin{array}{l}\text { PHA }(70 h) \\
\text { S phase }\end{array}$ \\
\hline WBC & $0.897^{*}$ & $0.743^{*}$ & $0.503^{\ddagger}$ & 0.213 & 0.224 & $-0.386^{\S}$ \\
\hline Granulocytes & & $0.505^{\ddagger}$ & $0.389^{\S}$ & 0.135 & 0.319 & -0.258 \\
\hline Monocytes & & & $0.408^{8}$ & $0.435^{\S}$ & 0.005 & $-0.538^{\ddagger}$ \\
\hline NK (CD56) & & & & $0.408^{\S}$ & 0.245 & -0.266 \\
\hline NK activity & & & & & -0.220 & $-0.443^{\S}$ \\
\hline RPMI (70 h) S phase & & & & & & 0.274 \\
\hline
\end{tabular}

${ }^{*} P<0.01 ; \quad{ }^{\ddagger} P<0.05 ; \quad{ }^{\S} P=0.06-0.10$.

only significant difference $(P<0.05)$ occurred between cortisol levels at SD15 $(M=2.73 \mu \mathrm{g} / \mathrm{dl})$ and R15 $(M=4.92 \mu \mathrm{g} / \mathrm{dl})$. ACTH showed no statistically reliable variation across days $\left(F_{4,44}=2.1\right)$.

Relationships among immune variables affected by sleep loss. Correlational analyses were carried out to determine the extent to which those subjects with the greater changes during sleep deprivation in a particular immune parameter also tended to have the greater changes in other immune parameters as a function of sleep loss. For those immune variables that appeared to be affected by sleep loss, change scores were obtained by subtracting each subject's value at SD15 from the value at SD63. Table II displays the Spearman rank order correlation coefficients evaluating the extent to which the change scores for a given immune parameter were correlated with change scores for other immune parameters.

A significant positive coefficient between WBC and granulocyte numbers $(\rho=0.897, P<0.01)$ provides evidence for interval validity. In that granulocytes are $\sim 75 \%$ of leukocytes, there should necessarily be a high correlation; thus, those subjects with greater increases in granulocytes during sleep loss also had greater increases in WBC. Monocytes make up about $5 \%$ of WBC, yet the change scores for them across deprivation also correlated highly with total WBC count $(\rho=0.743, P$ $<0.01)$. In addition, a significant relationship between change scores for granulocytes and monocytes $(\rho=0.505, P<0.05)$ was obtained. Subjects who had greater increases in numbers of granulocytes across days without sleep also tended to have greater increases in numbers of monocytes. There was a trend for NK (CD56) cell count change scores to correlate with changes in granulocyte $(\rho=0.389, P<0.10)$ and monocyte $(\rho$ $=0.408, P<0.08)$ counts, but only total WBC counts were significantly related to CD56 counts $(\rho=0.503, P<0.05)$. Changes in NK activity across deprivation were not significantly related to other parameters, although there were trends for positive relationships with changes in the numbers of monocytes $(\rho=0.435, P<0.06)$ and CD56 cells $(\rho=0.408, P$ $<0.08)$.

S-phase (DNA replication) cell percentages after $70 \mathrm{~h}$ of incubation in PHA were negatively correlated with changes in the number of monocytes $(\rho=-0.538, P<0.05)$, and there were trends for negative associations with changes in NK activity $(\rho=-0.443, P<0.06)$ and with total WBC counts $(\rho$ $=-0.386, P<0.10)$. Thus, subjects who evidenced greater increases in monocytes, total WBC, and NK activity during deprivation tended to have smaller increases in the percentage of lymphocytes in S phase after $70 \mathrm{~h}$ of incubation in PHA.
Changes in the proportion of lymphocytes in the $\mathrm{S}$ phase after $70 \mathrm{~h}$ of incubation in RPMI control medium were not correlated with changes in other immune parameters affected by sleep loss.

Effects of recovery sleep. Dependent $t$ tests were conducted to provide more detailed information on the extent to which recovery sleep had two effects: $(a)$ change from maximum sleep loss (i.e., SD63 to R15); and (b) return to predeprivation levels (i.e., SD15 to R15). Table III displays the results of dependent $t$ tests between SD63 and R15, and SD15 and R15; for comparison, the effects of sleep deprivation from SD15 to SD63 are also shown. Immune variables listed in Table III include only those for which a statistically significant change from SD15 to SD63 was observed by dependent $t$ test.

Recovery sleep resulted in a reversal of sleepiness and performance failures as reflected in neurobehavioral measures (Fig. 2). Subjective sleepiness ratings showed full recovery, declining from SD63 to $\mathrm{R} 15(t=7.84, P=0.0001)$ to a level indicative of slightly less sleepiness at $\mathrm{R} 15$ relative to predeprivation at $\operatorname{SD} 15(t=2.14, P=0.045)$. Vigilance performance lapses showed nearly full recovery, declining from SD63 to $\mathrm{R} 15(t=7.32, P=0.0001)$, while remaining slightly but significantly above the predeprivation SD15 level $(t=-2.62, P$ $=0.017$ ). The difference between subjective sleepiness and performance lapses after recover, relative to their respective predeprivation levels, is often observed in sleep deprivation studies; performance recovery lags temporally relative to self-estimates of sleepiness.

NK activity showed full recovery (Fig. 4), being significantly reduced at $\mathrm{R} 15$ relative to $\operatorname{SD63}(t=2.41, P=0.026)$, resulting in no statistically significant difference in NK activity between predeprivation and recovery levels $(t=-1.50)$. Monocyte counts (Fig. 3 ) also showed nearly complete recovery, being significantly reduced from SD63 to R15 $(t=3.28, P$ $=0.004)$, which resulted in only a marginal elevation above the SD15 predeprivation level $(t=-1.88, P=0.075)$. Less complete recovery was seen for WBC and granulocyte counts (Fig. 3). Both showed nonsignificant declines from SD63 to R15, but enough subjects declined to also yield no significant difference with the SD15 predeprivation average.

Cell cycle percentages from analysis of lymphocyte DNA after $70 \mathrm{~h}$ of incubation in PHA showed no change from SD63 to $\mathrm{R} 15$. The proportion of cells in the prereplication phase $\mathrm{G}_{0} / \mathrm{G}_{1}$ was unchanged at $\mathrm{R} 15$ relative to maximum sleep loss $(t$ $=-0.39$ ), remaining significantly below the SD15 predeprivation mean $(t=2.80, P=0.011)$. As evidenced in the top panel of Fig. 5, recovery sleep not only did not reverse the increased 
Table III. Summary of Dependent $t$ Test Results on the Extent to Which Recovery Sleep Reversed the Effects of Sleep Loss

\begin{tabular}{llll}
\hline & (SD15 to SD63) & (SD63 to R15) & (SD15 to R15) \\
\hline $\begin{array}{l}\text { Neurobehavioral } \\
\text { measures }\end{array}$ & & & \\
$\begin{array}{c}\text { Stanford Sleepiness } \\
\text { Scale } \\
\text { Vigilance } \\
\text { performance }\end{array}$ & $\uparrow(0.0002)$ & $\downarrow(0.0001)$ & $\downarrow(0.045)$ \\
$\quad$ lapses & & & \\
$\begin{array}{c}\text { Phenotype enumeration } \\
\text { WBC }\end{array}$ & $\uparrow(0.0001)$ & $\downarrow(0.0001)$ & $\uparrow(0.017)$ \\
$\begin{array}{l}\text { Granulocytes } \\
\text { Monocytes }\end{array}$ & $\uparrow(0.012)$ & & \\
$\begin{array}{c}\text { NK cell activity } \\
\text { Percent cytotoxicity }\end{array}$ & $\uparrow(0.002)$ & & \\
$\begin{array}{c}\text { DNA analysis } \\
\text { PHA at } 70 \text { h: GolG } \\
\text { phase }\end{array}$ & $\uparrow(0.0002)$ & $\downarrow(0.026)$ & \\
PHA at 70 h: S phase & $\uparrow(0.002)$ & $\uparrow(0.074)$ & $\uparrow(0.0001)$ \\
\hline
\end{tabular}

Arrow indicates direction of change $(P=)$.

proportion of cells at SD63 in the S phase after $70 \mathrm{~h}$ of incubation in PHA, but there was a trend for further increase (3.1\%) after recovery sleep $(t=-1.88, P=0.074)$, resulting in an average of $11 \%$ more cells in S phase at R15 than at predeprivation $\operatorname{SD} 15(t=-5.16, P=0.0001)$.

The effects of R15 on cell cycle percentages for $70 \mathrm{~h}$ of incubation in RPMI control medium were not included in Table III because there were only marginal changes $(0.05<P$ $>0.11$ ) in percentages from SD15 to SD63. Although the effect of sleep deprivation on cell cycle percentages from lymphocytes incubated in the control medium was modest, the effect of recovery sleep was robust, as seen in Fig. 5. The proportion of cells in S phase was reduced 11.5\% from SD63 to R15 ( $t$ $=6.31, P=0.0001)$, resulting in the percentage at R15 being significantly $(P=0.01)$ below all points except baseline.

\section{Discussion}

Acute sleep loss produced fatigue and cognitive performance failures in all subjects, consistent with its effects on brain function $(2,21)$. These neurobehavioral changes were paralleled by increases in peripheral blood counts of total WBC, granulocytes and monocytes, indicative of physiologic leukocytosis, and by increased NK activity. This pattern was strikingly consistent among subjects, regardless of gender, race, or time of year of study (e.g., 19/20 subjects had increased monocyte counts; $19 / 20$ had increased NK activity). The increases ranged from $13 \%$ to $36 \%$ of predeprivation values for WBC, granulocytes, and monocytes, and $14 \%$ for NK activity. This is the first time such a pattern has been observed in healthy young adults deprived of sleep. Collectively these changes suggest activation of nonspecific immune parameters, rather than immune suppression.

The covariation of leukocytosis and NK activity with sleep loss and recovery sleep suggests that these aspects of immune function may be influenced by biological pressure for sleep. NK cells are large granular lymphocytes important for recognition and destruction of malignant and virally-infected cells; they can be cytotoxic for tumor cells without prior sensitization (22). The increase of NK activity during sleep loss contrasts with findings of NK activity decreases in adults exposed to acute behavioral stressors $(23,24)$, and in depressed patients (25). NK activity has recently been shown to be negatively correlated with subjective symptoms of insomnia (26-28), and positively correlated with polysomnographic measures of total sleep time, sleep efficiency, and non-REM sleep duration (29). Increases in each of these parameters is evidence of elevated sleep pressure (i.e., the tendency to sleep). Interestingly, we found that NK activity increased following two nights, but not one night, without sleep. This outcome is consistent with the results of Moldofsky et al. (9), who reported that $40 \mathrm{~h}$ of sleep loss had no clear effects on NK activity, but in a subsequent study found that $64 \mathrm{~h}$ without sleep elevated NK activity during the early evening hours (10). The lag in NK activity in response to sleep loss may reflect the transient decreases in NK cell counts we observed after the first night without sleep.

Monocytes may have played a key role in the immune response to sleep loss. The magnitude of the increases in monocyte counts across sleep deprivation positively correlated with increases in total WBC, granulocyte counts, and NK activity. Monocytes may have affected NK activity through secretion of cytokines. NK cells are activated by cytokines such as IL- ${ }_{\beta}$, IFN ${ }_{\gamma}$, and IL-6; for example, IL- $1_{\beta}$, which is secreted by monocytes, can activate NK cells both directly and indirectly via IFN $_{\gamma}(30)$. Cytokines have been implicated in the regulation of sleep, and in the response to sleep loss. Studies on rabbits and rats of intracerebroventricular administration of IL- $1_{\beta}$, IFN $_{\gamma}$, and $\mathrm{TNF}_{\alpha}$ have demonstrated that these proteins have somnogenic effects independent of their pyrogenic effects (31-33). In non-sleep-deprived humans, cytokines can be difficult to detect in plasma (34), but there is evidence of them in plasma during sleep deprivation. Palmblad et al. (7) found increased IFN production during and after $77 \mathrm{~h}$ of sleep loss. Moldofsky et al. (9) found that $40 \mathrm{~h}$ of sleep deprivation enhanced IL-1like and IL-2-like activities.

Enumeration of B lymphocytes and most subsets of T cells showed no systematic changes across sleep deprivation, but there was evidence during the first 15-39 $\mathrm{h}$ without sleep for decreases of $\sim 8 \%$ in CD4 counts, $17 \%$ in CD56 counts, $16 \%$ in CD57 counts, and 32\% in CD16 counts. CD4 and CD16 counts remained reduced as sleep loss progressed to $63 \mathrm{~h}$, while CD56 and CD57 counts increased. Although reduction of CD4, CD8, CD16, CD56, and CD57 cell percentages are among the more common findings reported in studies of human immune responses to various types of life stressors (35), decreases in these cell populations after the first night without sleep may not reflect a nonspecific stressor effect in our experiment. There was no behavioral or physiological evidence of distress following the first night without sleep. Subjects were not depressed, angry, anxious, or unhappy on the mood scale assessments. Plasma levels of cortisol and ACTH did not show evidence of hypothalamic-pituitary-adrenal activation, although receptor studies would be needed to resolve this issue further. By $63 \mathrm{~h}$ without sleep the neurobehavioral effects of sleep loss were greater than at $39 \mathrm{~h}$, but there was still little evidence of distress from mood profiles, behavioral observations, or glucocorticoid levels. This raises the possibility that the observed transient decreases in lymphocyte counts after a single night without sleep reflect something other than distress, and that they may simply be an initial phase of a more complicated response leading to activation of immune responses rather than suppression. Distress reactions are not an inevita- 
ble consequence of sleep deprivation in the laboratory. Other studies have also failed to find elevated plasma levels of glucocorticoids $(2,36,37)$, even up to $205 \mathrm{~h}$ without sleep $(38,39)$. When elevations were observed, the experiments involved intensive physical (40) or mental (41) demands. Similarly, in rodent studies, plasma levels of corticosterone and ACTH were not elevated above levels for yoked controls until many days into the deprivation, proximal to fatality $(42,43)$. On the other hand, there was evidence early in deprivation of rats of elevated plasma norepinephrine. Although human sleep deprivation studies have not observed evidence of sympathetic nervous system alterations during sleep deprivation $(2,37,38)$, we cannot rule out the possibility that catecholaminergic changes mediated some of the immune effects we observed during sleep loss.

DNA analyses were done to reflect changes in lymphocyte proliferative capacity. Sleep loss was associated with increases in the proportion of cells in S phase after incubation in PHA for $70 \mathrm{~h}$, which is not consistent with the lack of increased total lymphocyte numbers or increased proliferative responses to PHA. There was no systematic elevation in S phase percentage until the maximum time of sleep loss, and there was no reduction after recovery sleep, resembling the pattern seen for CD56 and CD57 cell counts. It is not clear, however, that the DNA synthesis pattern and the pattern of lymphocyte counts share a common variance, since there were negative correlations between change in S-phase cell percentage and changes in both CD56 cell counts and monocyte counts across deprivation. Subjects with larger increments in monocyte counts during deprivation tended to have smaller increments in the proportion of cells in $\mathrm{S}$ phase, and vice versa. This finding suggests that the rise in monocytes accompanying sleep loss may be associated with concomitant inhibition of increases in lymphocytes. The process by which this could occur is unknown, since these phenomena are normally synergistic.

Finally, we note that despite neurobehavioral impairments, leukocytosis, and NK activation at $63 \mathrm{~h}$ without sleep, there was no clinical evidence of infectious illness either during, or up to 9 days after, sleep deprivation. It remains to be determined whether the changes observed in immune cell trafficking patterns during sleep deprivation occurred at a subclinical level or actively altered the vulnerability to infection. The findings support the hypothesis that sleep loss can alter immune function, but there was no immunologic or clinical evidence to support the hypothesis that these alterations are in the direction of immune decreases, and no psychological or glucocorticoid evidence to support the hypothesis that the immune changes resulted from a nonspecific stress response. However, given the disparity between the effects of one versus two nights without sleep on immune parameters, even more severe sleep loss may result in failure of immune function, as has been suggested may occur in the lethal outcome studies of rats deprived of sleep for many days (44). Our data indicate that acute loss of sleep to the point of impairment of neurobehavioral function in humans is associated with leukocytosis and increased NK cell counts and activity, and that these outcomes are reversed by recovery sleep.

\section{Acknowledgments}

For help in study planning, logistics, and data acquisition, we thank Dr. Steven E. Keller, Darcy L. Reber, Barbara A. Haupt, Andrea M. Laizner, Paul Ukpah, Kelly A. Gillen, John W.
Powell, Michele M. Carlin, Dr. Nancy Barone Kribbs, Dr. Brad L. Bates, Dr. Jay Getsy, Dr. Joanne E. Getsy, Jeanne S. Schuett, John Henry, Kathleen M. Allen, Allison Cromwell, Amy R. Weeks, Angela D. Touhey, Peg Coley, Hans Hassinger, Dr. Laurie Kilpatrick, Dr. Andrew Winokur, Dr. Albert Lee, Dr. Larry Leventhal, and Dr. Mark R. Rosekind and NASA Ames Research Center.

This study was supported by grant $\mathrm{MH}-44193$ from the National Institute of Mental Health, National Institutes of Health (NIH), and by the Institute for Experimental Psychiatry Research Foundation. Portions of the work were also supported by NIH grant CRC RR 00040, and grant NCC-2-599 from NASA.

\section{References}

1. Wake Up America: A National Sleep Alert. 1993. A Report of the National Commission on Sleep Disorders Research. Vol. 1: Executive Summary and Executive Report. National Institute of Aging, Washington, DC. 76 pp.

2. Horne, J. 1988. Why We Sleep: The Functions of Sleep in Humans and Other Animals. Oxford University Press, Oxford. 319 pp.

3. Norman, S. E., L. Resnick, M. A. Cohn, R. Duara, J. Herbst, and J. R. Berger. 1988. Sleep disturbances in HIV seropositive patients (letter). JAMA (J. Am. Med. Assoc.) 260:922.

4. Brown, R., G. Pang, A. J. Husband, and M. G. King. 1989. Suppression of immunity to influenza virus infection in the respiratory tract following sleep disturbance. Reg. Immunol. 2:321-325.

5. Brown, R., R. J. Price, M. G. King, and A. J. Husband. 1989. Interleukin-1 $\beta$ and muramyl dipeptide can prevent decreased antibody response associated with sleep deprivation. Brain Behav. Immun. 3:320-330.

6. Benca, R. M., C. A. Kushida, C. A. Everson, R. Kalski, R., B. M. Bergmann, and A. Rechtschaffen. 1989. Sleep deprivation in the rat. VII. Immune function. Sleep. 12:47-52.

7. Palmblad, J., K. Cantell, H. Strander, J. Froberg, C. Karisson, L. Levi, M Granstrom, and P. Unger. 1976. Stressor exposure and immunological response in man: interferon-producing capacity and phagocytosis. J. Psychosom. Res. 20:193-199.

8. Palmblad, J., B. Petrini, J. Wasserman, and T. Akerstedt. 1979. Lymphocyte and granulocyte reactions during sleep deprivation. Psychosom. Med. 41:273-278.

9. Moldofsky, H., F. Lue, J. Davidson, and R. Gorczynski. 1989. Effects of sleep deprivation on human immune functions. FASEB J. 3:1972-1977.

10. Moldofsky, H., F. Lue, J. Davidson, J. Jephthah-Ochola, K. Carayanniotis, and R. Gorczynski. 1989. The effect of 64 hours of wakefulness on immune functions and plasma cortisol in humans. In Sleep '88. J. Horne, editor. Gustav Fischer Verlag, Stuttgart. 185-187.

11. Boyum, A. 1968. Isolation of mononuclear cells and granulocytes from human blood: isolation of mononuclear cells by centrifugation and sedimentation at 1 g. Scand. J. Clin. Lab. Invest. 21(Suppl. 97):77-89.

12. Garty, B.-Z., A. Levinson, Y. L. Danon, R. Wilmott, and S. D. Douglas, 1989. Lymphocyte subpopulations in children with abnormal lymphatic circulation. J. Allergy Clin. Immunol. 84:515-520.

13. Keller, S. E., S. J. Schleifer, J. Sherman, M. Camerino, H. Smith, Jr., and M. Stein. 1981. Comparison of a simplified whole blood and isolated lymphocyte stimulation technique. Immunol. Commun. 10:417-431.

14. Georgescu, R., and S. E. Keller. 1987. Decreasing the spontaneous release in NK cell assays. J. Immunol. Methods. 103:143.

15. Georgescu, R., and S. E. Keller. 1987. Overnight storage at $1^{\circ} \mathrm{C}$ does not affect NK cytotoxicity. J. Immunol. Methods. 103:151.

16. Shapiro, H. M. 1989. Flow cytometry of DNA content and other indicators of proliferative activity. Arch. Pathol. Lab Med. 113:591-597.

17. Hoddes, E., V. Zarcone, H. Smythe, R. Phillips, and W. C. Dement. 1973. Quantification of sleepiness: a new approach. Psychophysiology. 10:431-436.

18. Lisper, H., and A. Kjellberg. 1972. Effects of a 24-hour sleep deprivation on rate of decrement in a 10-minute auditory reaction time task. J. Exp. Psychol. 96:287-290.

19. Glenville, M., R. Broughton, A. M. Wing, and R. T. Wilkinson. 1978. Effects of sleep deprivation on short duration performance measures compared to the Wilkinson Auditory Vigilance Task. Sleep. 1:169-176.

20. Dinges, D. F., M. T. Orne, W. G. Whitehouse, and E. C. Orne. 1987. Temporal placement of a nap for alertness: contributions of circadian phase and prior wakefulness. Sleep. 10:313-329.

21. Dinges, D. F., and N. B. Kribbs. 1991. Performing while sleepy: effects of experimentally-induced sleepiness. In Sleep, Sleepiness and Performance, T. H. Monk, editor. John Wiley \& Sons, Chichester. 97-128. 
22. Roitt, I. 1991. Essential Immunology. Blackwell Scientific Publications, Oxford. 356 pp.

23. Kiecolt-Glaser, J., W. Garner, C. Speicher, G. Penn, J. Holliday, and R. Glaser. 1984. Psychosocial modifiers of immunocompetence in medical students. Psychosom. Med. 46:7.

24. Kiecolt-Glaser, J., R. Glaser, E. Strain, J. Stout, K. Tarr, J. Holliday, and C. Speicher. 1986. Modulation of cellular immunity in medical students. J. Behav. Med. 9:5-12.

25. Evans, D., J. Folds, J. Pettito, R. Golden, C. Pedersen, M. Corrigan, J. Gilmore, S. Silva, D. Quade, and H. Ozer. 1992. Circulating natural killer cell phenotypes in men and women with major depression: relation with cytotoxic activity and major depression. Arch. Gen. Psychiatry. 49:388-395.

26. İrwin, M., M. Daniels, T. Smith, E. Bloom, and H. Weiner. 1987. Life events, depressive symptoms, and immune function. Am. J. Psychiatry. 144:437441.

27. Irwin, M., T. Smith, and J. Gillin. 1987. Low natural killer cytotoxicity in major depression. Life Sci. 41:2127-2133.

28. Irwin, M., C. Caldwell, T. Smith, S. Brown, M. Schuckit, and J. Gillin. 1990. Major depressive disorder, alcoholism, and reduced natural killer cytotoxicity: role of severity of depressive symptoms and alcohol consumption. Arch. Gen. Psychiatry. 47:713-719.

29. Irwin, M., T. Smith, and J. Gillin. 1992. Electroencephalographic sleep and natural killer activity in depressed patients and control subjects. Psychosom. Med. 54:10-21.

30. Dinarello, C. A. 1988. Biology of interleukin 1. FASEB J. 2:108-115.

31. Krueger, J. 1990. Somnogenic activity of immune response modifiers. Trends Pharmacol. Sci. 11:122-126.

32. Krueger, J., and J. A. Majde. 1990. Sleep as a host defense: its regulation by microbial products and cytokines. Clin. Immun. Immunopathol. 57:188-199.

33. Opp, M., L. Kapas, and L. Toth. 1992. Cytokine involvement in the regulation of sleep. Proc. Soc. Exp. Bio. Med. 201:16-27.
34. Gudewill, S., T. Pollmacher, H. Vedder, W. Schreiber, K. Fassbender, and F. Holsboer. 1992. Nocturnal plasma levels of cytokines in healthy man. Eur. Arch. Psychiatry Clin. Neurosci. 242:53-56.

35. Kemeny, M. E., G. F. Solomon, J. E. Morley, and T. L. Herbert. 1992. Psychoneuroimmunology. In Neuroendocrinology. C. B. Nemeroff, editor. CRC Press, Boca Raton, FL. 563-591.

36. VanHelder, T., and M. W. Radomski. 1989. Sleep deprivation and the effect on exercise performance. Sports Med. 7:235-247.

37. Palmblad, J., T. Akerstedt, J. Froberg, A. Melander, and H. von Schenck. 1979. Thyroid and adrenomedullary reactions during sleep deprivation. Acta Endocrinol. 90:233-239.

38. Rubin, R. T., E. J. Kollar, G. G. Slater, and B. R. Clark. 1969. Excretion of 17-hydroxycorticosteroid and vanillymandelic acid excretion during 205 hours sleep deprivation in man. Psychosom. Med. 31:68-75.

39. Naitoh, P., A. Kales, E. J. Kollar, J. C. Smith, and A. Jacobson. 1969. Electroencephalographic activity after prolonged sleep loss. Electroencephalogr. Clin. Neurophysiol. 27:2-11.

40. Opstad, P. K., and A. Aakvaag. 1983. The effect of sleep deprivation on the plasma levels of hormones during prolonged physical strain and caloric deficiency. Eur. J. Appl. Physiol. Occup. Physiol. 51:97-107.

41. Radomski, M. W., L. E. M. Hart, J. M. Goodman, and M. J. Plyley. 1992. Aerobic fitness and hormonal responses to prolonged sleep deprivation and sustained mental work. Aviat. Space Environ. Med. 63:101-106.

42. Bergmann, B. M., C. A. Everson, C. A. Kushida, V. S. Fang, C. A. Leitch, D. A. Schoeller, S. Refetoff, and A. Rechtschaffen. 1989. Sleep deprivation in the rat. V. Energy use and mediation. Sleep. 12:31-41.

43. Rechtschaffen, A., B. M. Bergmann, C. A. Everson, C. A. Kushida, and M. Gilliland. 1989. Sleep deprivation in the rat. X. Integration and discussion of the findings. Sleep. 12:68-87.

44. Everson, C. A. 1993. Sustained sleep deprivation impairs host defense. Am. J. Physiol. 265:R1148-R1154. 